\title{
INVESTIGATION ON DISTRIBUTION OF CAST PROPERTIES ON ALUMINUM PLATES POURED BY SIDE GATING TECHNIQUE
}

\author{
J. Runyoro \\ P.O. Box 35131, Dar es salaam, Tanzania, East Africa \\ Email: owekisha@uccmail.co.tz
}

\begin{abstract}
Casting technologies which improve casting yield and internal soundness of thin wall cast components are of particular interest to industry especially for critical applications. The main aim of foundries is to achieve castings free from defects at low cost. It has been thought that pouring casting by side ingate technique improve directional solidification as the metal stays hot for long time in the feeder cum ingate. Experiments were carried out using a side gating technique to cast a number of $300 \mathrm{~mm} \times 300 \mathrm{~mm}$ LMO and LM 25 plates in furan and pepset sand moulds. The thickness used was 5 and $10 \mathrm{~mm}$ for furan and pepset sand moulds respectively. The plates were divided into sections and tests carried out. The variation in plate thickness with temperature as well with bending stress and crack length was observed and recorded in plates made out of LMO materials. Tensile tests were carried out on LM 25 alloy and the relationship between pouring temperature, pouring rate, plate thickness, and pouring time with specimen location with respect to ingate in the casting was established. Plates poured at low rates but high temperature or vice versa give consistent thickness values. High pouring temperature and pouring rates in sand moulds give uneven thickness along the plate casting. Thin castings poured by side gating technique showed a tendency of cracking in a three point bending test, exhibited high strength scatter and severe porosity in the casting. Majority of the cracks were less than $3 \mathrm{~mm}$ in length.
\end{abstract}

Key words: Side ingate technique, plate casting, porosity, strength, oxide films

\section{INTRODUCTION}

Casting technologies which improve casting yield and internal soundness of thin wall cast components is of particular interest to the industry especially for critical applications. Different methods have been developed to produce quality castings (Campbell 2003, Runyoro, 2006). The main aim of foundries was to achieve castings free from defects at low cost. The use of a bottom gate supplying a side riser connected to the edge of a vertical plate gives good feeding properties as it is expected that the metal flow will always pass through the feeder. The idea behind this approach, metal starts to rise at a rapid rate near the base of the plate and gradually slows down at the top of the plate. The hot metal at the top of the plate is assumed to feed the bottom part of the plate.

The ingate positioning with relation to mould cavity plays a great role in terms of the quality of the metal delivered to the mould cavity.

Bottom gating directs the metal in the lowest part of the casting with minimum turbulence [1]. The metal entry into the mould cavity is quiet, producing castings of high quality having high density and pressure tightness. By using vertical parting lines, runners may be molded below the casting allowing the ingates to enter the bottom of the casting cavity. Bottom gating is frequently used for dross forming alloys or those which are sensitive to turbulence. Top gating is designed such that the metal enters the top of the mould cavity and then falls to impinge against the bottom causing a strong circulation of the molten metal in the mould. In order to combine the good properties of top and bottom gating and leave out the disadvantages of these systems, the side pouring system has been introduced.

Attempts were made to find previous works based on side ingate technique in the sand moulds, but none was found, but nonetheless this technique is widely used in die casting. In this experimental setup for LMO and LM25 castings, wide spectrums of velocities were surveyed in a single casting. Oxide laps were expected to occur in castings poured at very low velocities. The density of cast plate samples can be obtained by using the electronic density measuring balance which utilizes the principle of volume displacement by submerged objects in water. Density of samples which displayed automatically by the balance is based on 
dividing weight in air by the weight in air minus weight in water. The percentage porosity of the plate was obtained by dividing the density of the plate with the highest density of all samples. This experiment attempts to establish the effect of pouring temperature and pouring rates on mechanical properties and directional solidification properties of the $5 \mathrm{~mm}$ and $10 \mathrm{~mm}$ thick LMO and LM25 plate castings.

\section{Experimental procedure}

\section{(i) Materials}

The mould used to cast $300 \mathrm{~mm} \times 300 \mathrm{~mm}$. plates of 5 and $10 \mathrm{~mm}$ thicknesses of LMO and LM25 Aluminum plates is shown in Fig. 1. The moulds were made out of furan bonded sand. Some of experiments in LM 25 were repeated and cast in Pepset bonded sand (a olyurethane based two part resin binder).

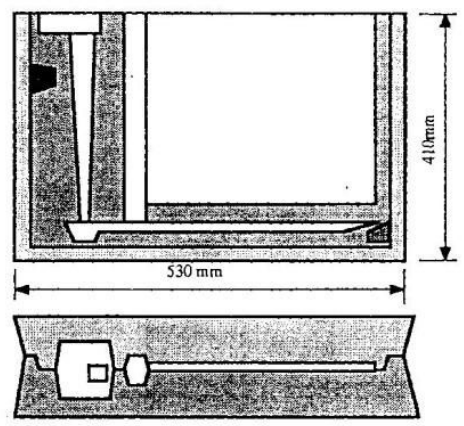

Fig. 1 The side gating technique mold used in these experiments

\section{(ii) Casting Technique}

Different pouring rates were achieved by varying the size of the tapered sprue choke area designed according to Campbell (2003). The sprue exit areas were 42, 82 and $169 \mathrm{~mm}^{2}$ respectively. In all moulds, a set of copper wires were passed through $5 \mathrm{~mm}$ diameter hand drilled holes into the mould cavity at 100, $200,290 \mathrm{~mm}$ to act as contacts when the molten metal touches them to record time taken to fill that level of cavity as shown in fig. 2. In order to find the relationship between pouring time and pouring rates, castings were weighed before and after removing the gating system.
The riser dimensions used for LMO were $25 \mathrm{x}$ $25 \mathrm{~mm}$ while for LM 25 were $25 \times 60 \mathrm{~mm}$ in cross sectional area. The increase in riser cross sectional area was made because of the desire to investigate the properties of alloy by pouring very slowly while making sure the metal does not solidify in the riser.

\section{(iii) Radiographic inspection}

Plates were inspected by radiographic method to find out whether they had any defects such as oxide laps. After examination of x-ray films, plates were divided and cut into sections for bending, tensile and density measurements. 


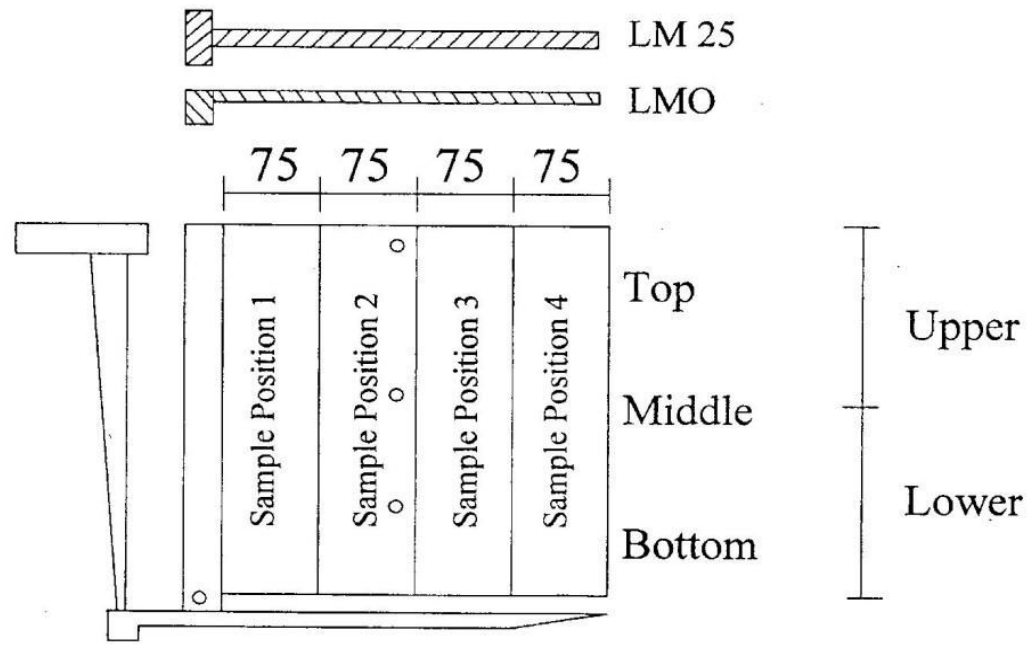

Fig. 2 Method used to identify samples in the $300 \times 300 \mathrm{~mm}$ cast plate. The upper cross sectional area shows the riser shape for LM 25 and LMO alloys.

\section{(iv) Bending and Tensile tests}

The partitioning of the plate was made according to fig. 2. This classification of the sample position in the plate has been widely used when plotting the properties of specimen taken from different location in graph form. The bending and tensile test specimens were 70 - $75 \mathrm{~mm}$ wide and $150 \mathrm{~mm}$ high. The supporting dies used in the bend test were 76 $\mathrm{mm}$ in diameter while the former radius was 25 $\mathrm{mm}$. The 180 degrees three-point bend test of the plates was carried out using a fixture fitted in a Universal tensile testing machine. The maximum bending forces were recorded and cracks opened up by bending were measured. Tensile test specimens were prepared and tested according to British Standard BS 1490 for sand cast aluminum and aluminum alloys. In all LMO specimens, thickness of samples, bending force and total crack length openings were measured. Tests carried out on LM 25 metal included tensile and density measurements.

\section{(v) Density measurements}

Density measurements were made using a balance with $500 \pm 0.001$ grams accuracy. Density measurements were carried out on all tensile tested specimens. The ultimate tensile strength, percentage elongation and percentage reduction in area was calculated. The chemical analyses of alloys used in this experiment are shown in Table. 1.

Table 1 Approximate chemical analysis of alloys.

\begin{tabular}{|l|l|l|l|l|l|l|l|l|l|}
\hline Material & $\mathrm{Al}$ & $\mathrm{Fe}$ & $\mathrm{Si}$ & $\mathrm{Mg}$ & $\mathrm{Ni}$ & $\mathrm{Mn}$ & $\mathrm{Cu}$ & $\mathrm{Zn}$ & $\mathrm{Ti}$ \\
\hline LMO & 99.91 & 0.06 & 0.03 & - & - & 0.002 & 0.002 & 0.018 & 0.001 \\
\hline LM 25 & 91.81 & 0.30 & 7.03 & 0.42 & 0.01 & 0.17 & 0.08 & 0.07 & 0.11 \\
\hline
\end{tabular}

\section{Results and Discussion}

(i) Effect of pouring rate and pouring temperature on dinensional tolerance of LMO cast plates

The thickness measurement results for cast LMO plates are shown in Fig. 3 and 4. For a 5 $\mathrm{mm}$ plate poured in furan sand, the thickness ranged between 3.6 to $6.5 \mathrm{~mm}$ depending on the specimen location, pouring time and pouring temperature. Sand moulds, when heated, tend to expand, the higher the molten metal temperature, the higher will be the mould deformation. Also the rate of the molten metal expansion depends on its temperature. When the metal solidifies, it shrinks, and if there is no liquid metal to feed the solidifying mass, the plate thickness at that point will be 
low. In areas were the mould expanded and there is enough metal to feeder to fill the gap during the solidification of the metal, then the thickness of the plate will be higher than the pattern dimensions. In few cases, partial opening up of the mould is not ruled out.

Plates poured at high temperature $\left(850^{\circ} \mathrm{C}\right)$ and high pouring rate $(427 \mathrm{ml} / \mathrm{s})$ have high thickness range shown in Table 2. The comparison to these values, when poured at the same rate but at $750^{\circ} \mathrm{C}$ temperature, the thickness decreases from bottom to the top. The values which tend to be consistent are the ones poured at low temperatures. The reduction in thickness below $5 \mathrm{~mm}$ for plates poured at low temperatures may be due to the fact that these sections acted like feeders to the remaining part of the plate and at the same time there was shrinkage solidification of the plates. At filling rate of $212 \mathrm{ml} / \mathrm{s}$ and pouring temperature of $850^{\circ} \mathrm{C}$ and $700^{\circ} \mathrm{C}$, the change in plate thickness is very minimal, while at a temperature of $750^{\circ} \mathrm{C}$, the thickness at the end of the plate opposite to the feeder is higher than that at the center line of the plate parallel to the feeder.

It was difficult to pour the metal at filling rate of $106 \mathrm{ml} / \mathrm{s}$ and temperatures of 750 and $700^{\circ} \mathrm{C}$ for a $5 \mathrm{~mm}$ plate casting, here, the metal solidified prematurely. The plate poured at $850^{\circ} \mathrm{C}$ and $106 \mathrm{ml} / \mathrm{s}$ gave consistent thickness results.

Table 2 Thickness measurements of the $300 \times 300 \mathrm{LMO}, 5 \mathrm{~mm}$ plates at different pouring temperatures and pouring rates.

\begin{tabular}{|c|c|c|c|c|}
\hline \multirow{2}{*}{$\begin{array}{c}\text { Pouring Temp } \\
\left({ }^{\circ} \mathbf{C}\right)\end{array}$} & $\begin{array}{c}\text { Pouring rate } \\
(\mathrm{ml} / \mathbf{s})\end{array}$ & Bottom & Middle & Top \\
\cline { 3 - 5 } & 427 & $5.50-5.90$ & $5.80-6.10$ & $6.40-6.50$ \\
\hline 850 & 427 & 5.30 & $4.50-4.60$ & $3.60-4.20$ \\
\hline 750 & 427 & $5.80-6.0$ & $5.80-5.90$ & $5.60-5.90$ \\
\hline 700 & 212 & $5.50-5.60$ & $5.50-5.60$ & $5.40-5.60$ \\
\hline 850 & 212 & $5.28-5.80$ & $4.50-5.44$ & $3.60-5.40$ \\
\hline 750 & 212 & $5.38-5.90$ & $5.28-6.00$ & $5.32-5.9$ \\
\hline 700 & 106 & $5.70-6.00$ & $5.80-6.18$ & $5.90-6.00$ \\
\hline 850 & & & & \\
\hline
\end{tabular}

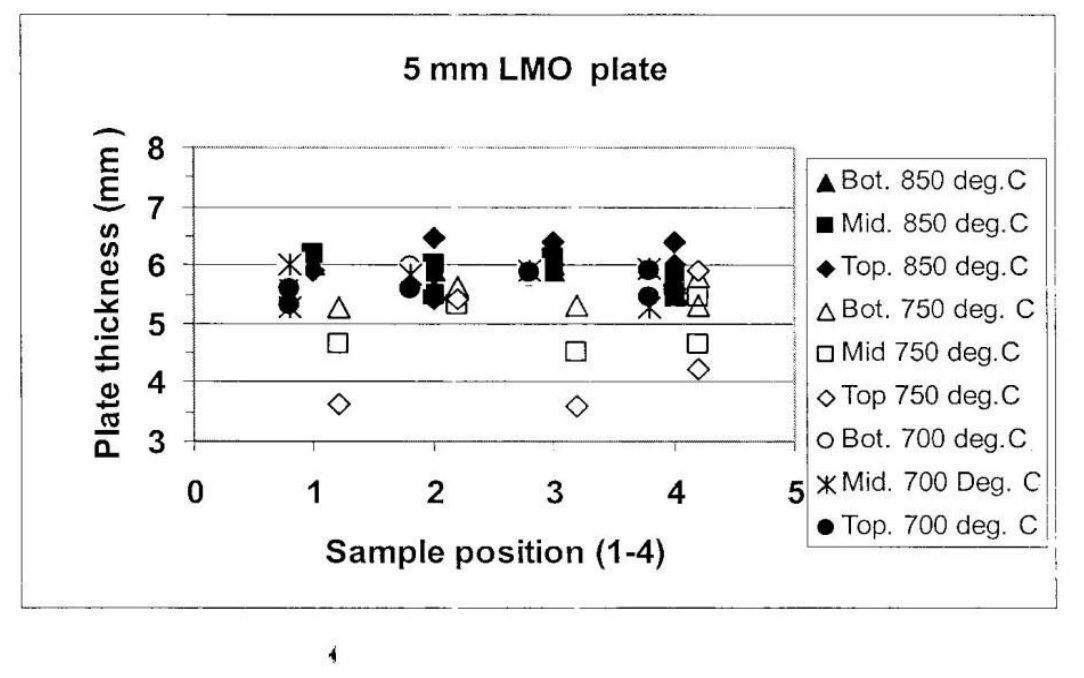




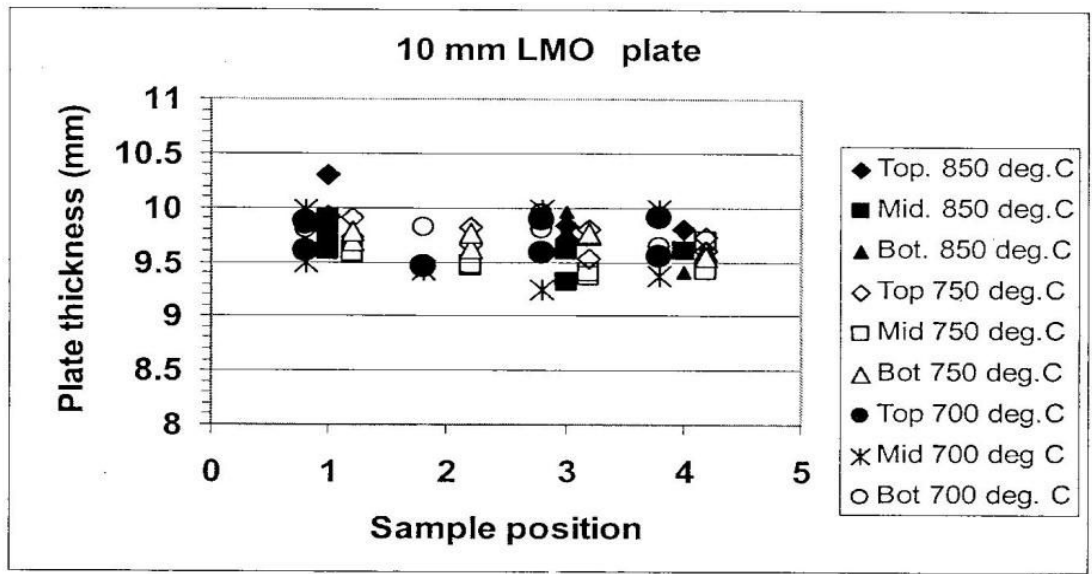

Fig. 3 Variation in thickness of 5 and $10 \mathrm{~mm}$ plates of $300 \times 300 \mathrm{~mm}$ size.

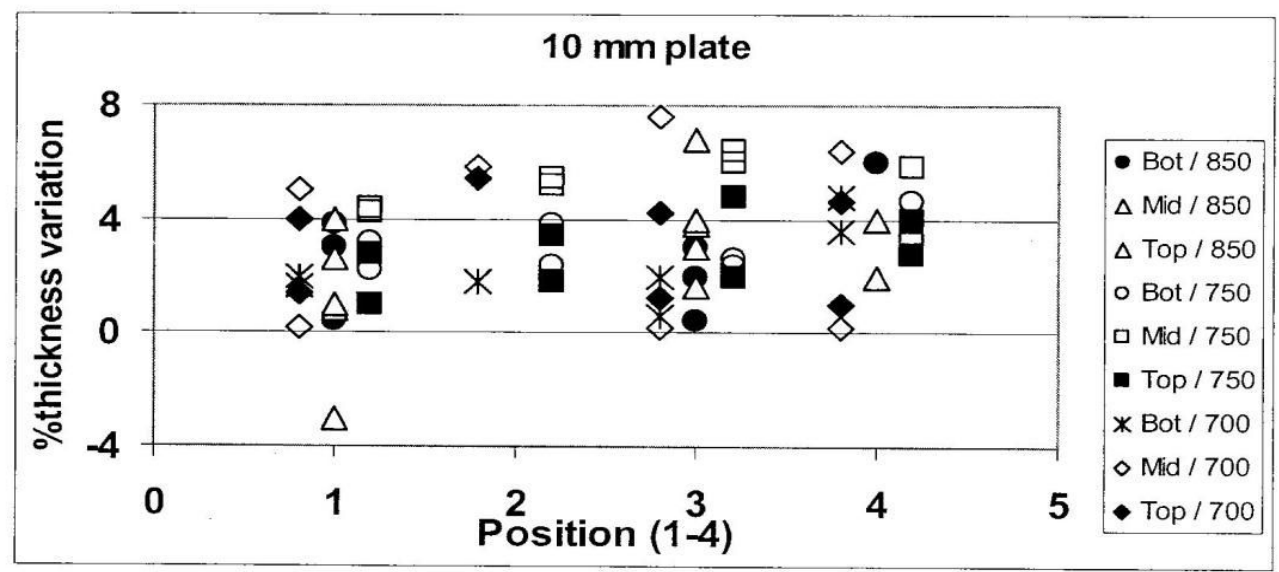

Fig. 4 Effect of temperature and position on plate thickness percentage variation for $300 \times 300$ mm LMO plate castings.

For the $10 \mathrm{~mm}$ plates poured at $850^{\circ} \mathrm{C}$, The plate thickness at the top and bottom are higher than those in the middle of the plate (Fig. 3 and 4). Most of measured values of the plates lie between 9.5 to $10 \mathrm{~mm}$ except for a few measurements taken in the middle of the plate in positions 3 and 4 . This shows that there was a feeding difficulty in those locations. The pouring temperature of $700^{\circ} \mathrm{C}$ and filling rates of $427 \mathrm{ml} / \mathrm{s}$ gives consistent thickness in the 10 $\mathrm{mm}$ LMO plates. The LMO alloy solidification behavior are different to that of LM25 alloy under the same casting condition and mould conditions due to the fact that the coefficient of expansion of LMO is higher than that of LM25. (ii) Effect of thickness, pouring rate and pouring temperature on bending strength of LMO plate alloys

In order to quantify the integrity of the cast plate, a three bend test was carried out to find out the weak point in the plate surface as it is known that pure aluminum alloys have very high ductility. The three-point bending stress and crack length results for a 5 and $10 \mathrm{~mm}$ thick plate are shown in Fig. 5. The 180 degrees bending stress of $5 \mathrm{~mm}$ plates range between 1.1 - 3.4 MPa. The highest values greater than 3 $\mathrm{MPa}$ were obtained when the sample was close to the feeder and or at high filling rates. Samples with high pouring temperature and high filling rates, and taken from position 3 and 4 in the plate were the ones with very low bending stresses of 1.1 $\mathrm{MPa}$, compared to those 
taken from the sides. Although the bending stress were low in this positions, only one sample showed a surface crack. This shows that the weakness of the casting can also be inside the casting, and not opening up at the surface. Over sixty percent of all $5 \mathrm{~mm}$ plate specimens poured at $850^{\circ} \mathrm{C}$ failed by cracking, although the bending stress was above $2 \mathrm{MPa}$ in most cases (Fig.7). It is very easy to form an oxide film at high temperatures which losses strength with time and therefore becomes the weak point in the casting (Runyoro, 2006; Eklund, 1991).

In $10 \mathrm{~mm}$ plates, the bending stress varied from 3.3 to $6.8 \mathrm{MPa}$. The highest values of bending stress were obtained when the metal was poured at $700^{\circ} \mathrm{C}$ with filling rates of $427 \mathrm{ml} / \mathrm{s}$ followed by plates poured at $850^{\circ} \mathrm{C}$ and $750^{\circ} \mathrm{C}$ respectively.
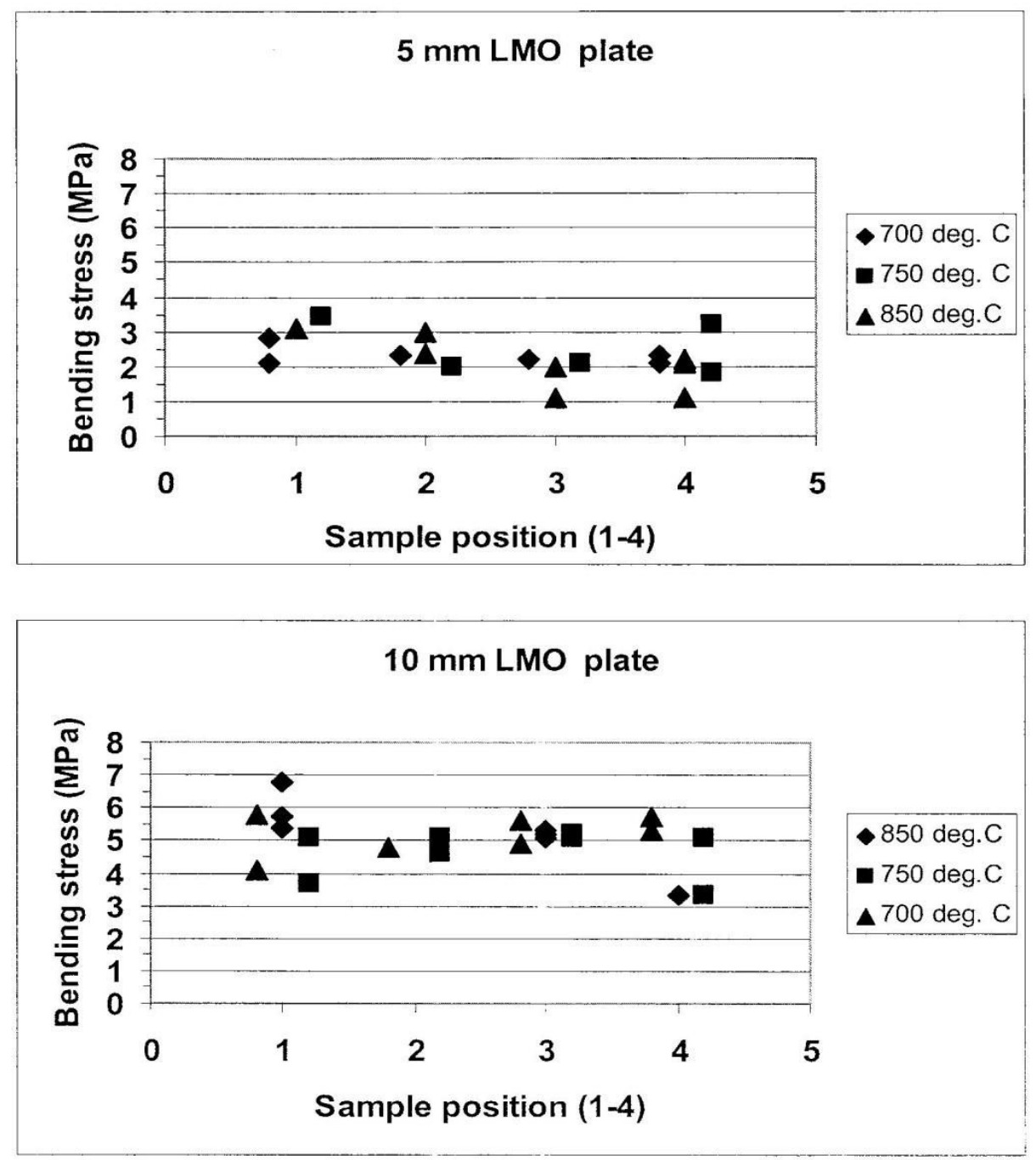

Fig. 5. Variation of bending stress in a 5 and $10 \mathrm{~mm}$ plates with $300 \times 300 \mathrm{~mm}$ sizes.

Thirty six percent of all $10 \mathrm{~mm}$ thickness plates tested, cracked including those which exhibited high bending stresses. Fig. 5 show that the bending stresses close to the riser are generally higher than those in the far end of the plate due to better feeding bending stresses of molten metal during solidification. The normalized bending stresses to the thickness of the plates are shown in fig. 6 . The size effect plays an important part as values for thin section plates are lower when compared to those of thick section plates. 


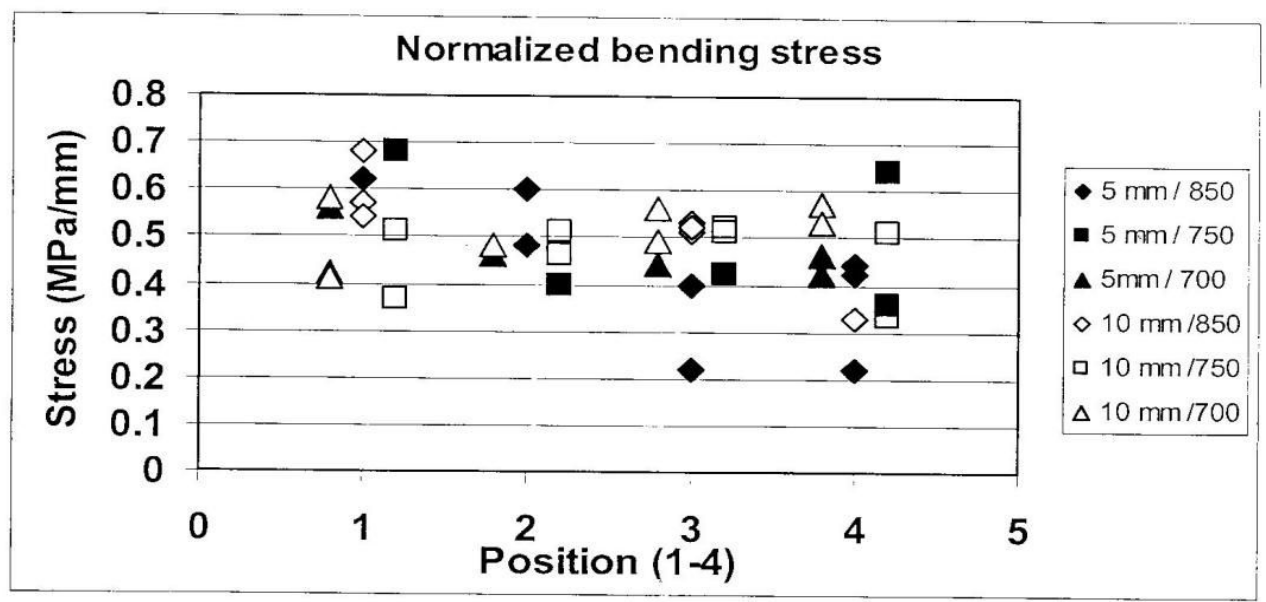

Fig. 6 Effect of temperature and position on normalized Bending Stress (MPa) for a $300 \times 300$ mm LMO plate castings

The longest surface cracks occurred at positions 3 for 5 and $10 \mathrm{~mm}$ thickness plates when poured at temperatures of $850^{\circ} \mathrm{C}$ and at rates of $106 \mathrm{ml} / \mathrm{s}$ for a $5 \mathrm{~mm}$ plate with bending stress of $2.0 \mathrm{MPa}, 205 \mathrm{ml} / \mathrm{s}$ for a $10 \mathrm{~mm}$ plate with bending stress of $5.1 \mathrm{MPa}$. These bending stresses represent $59 \%$ for $5 \mathrm{~mm}$ plate and $75 \%$ for $10 \mathrm{~mm}$ plate, of the maximum bending stress recorded in the experiment. The initial pouring rate is presented by $21.2 \mathrm{ml} /$ (s.mm) and $20.5 \mathrm{ml} /$ (s.mm) for 5 and $10 \mathrm{~mm}$ plates respectively. Very low pouring rates of less than $10 \mathrm{ml} /$ (s.mm) at high temperatures causes the oxide film thickness to grow thus reducing its strength.

For a $5 \mathrm{~mm}$ plate, the strength and elongation of adjacent plates range from 48.2 to $51.9 \mathrm{MPa}$ and from 20 to $30 \%$ for section 2 and from 49.5 to $50.4 \mathrm{MPa}$ and from 22 to $26 \%$ for section 4 respectively. For a $10 \mathrm{~mm}$ plate, the strength and elongation of adjacent plates range from 42.1 to $48.8 \mathrm{MPa}$ and from 16 to $22 \%$ for section 2 and from 50.7 to $50.9 \mathrm{MPa}$ and from 30 to $40 \%$ for section 4 . Over eighty percent of all cracks formed in 5 and $10 \mathrm{~mm}$ plates are below $5 \mathrm{~mm}$ in length, while sixty percent are below $3 \mathrm{~mm}$ in length (Figs. 7, 8 and 9). These crack were formed by oxide films opening up on the casting under bending around the middle of the plate. The crack length per unit casting width values are constant except in position three of the plate where they are occasionally much higher than those in the rest of the plate. Fig. 10 shows that there is no relation between the three point bending stress and the resulting crack in aluminum alloys. The opening up of the plate in bending is caused by the oxide film opening up especially those which are very thick. 

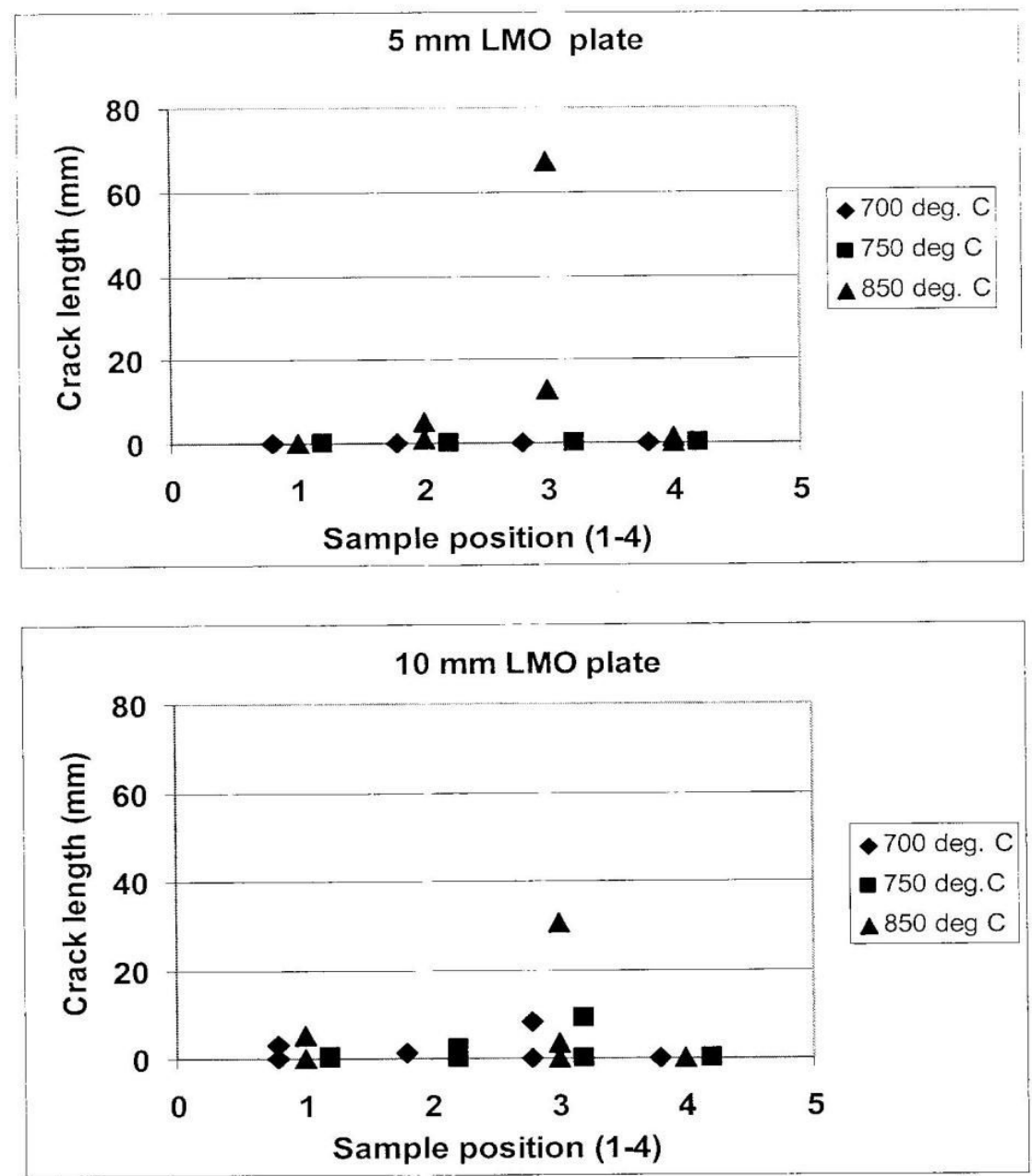

Fig. 7 Effect of temperature and position on crack length for a $300 \times 300 \mathrm{~mm}$ LMO plate castings.

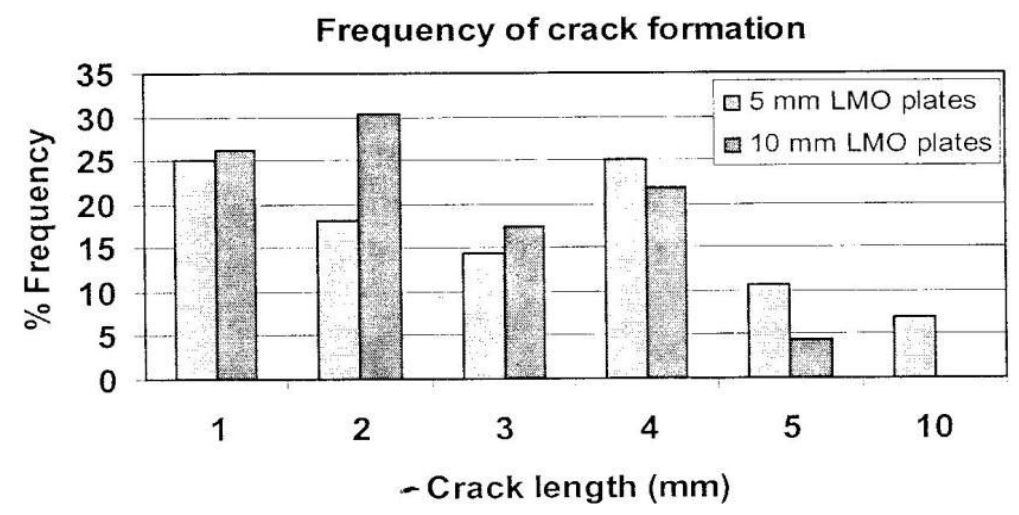

Fig. 8 Frequency of occurrence of cracks on 5 and $10 \mathrm{~mm}$ plate castings 


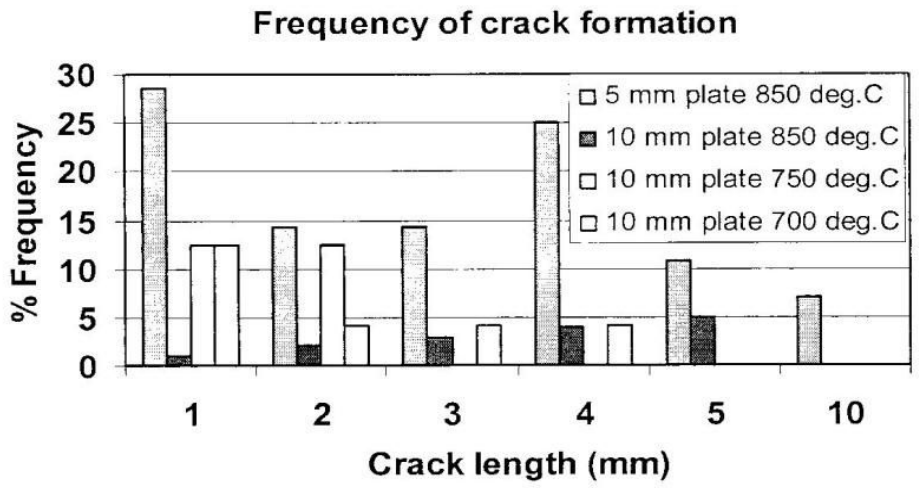

Fig. 9 Frequency of occurrence of cracks on a 5 and $10 \mathrm{~mm}$ LMO alloy plate castings with varying temperatures.

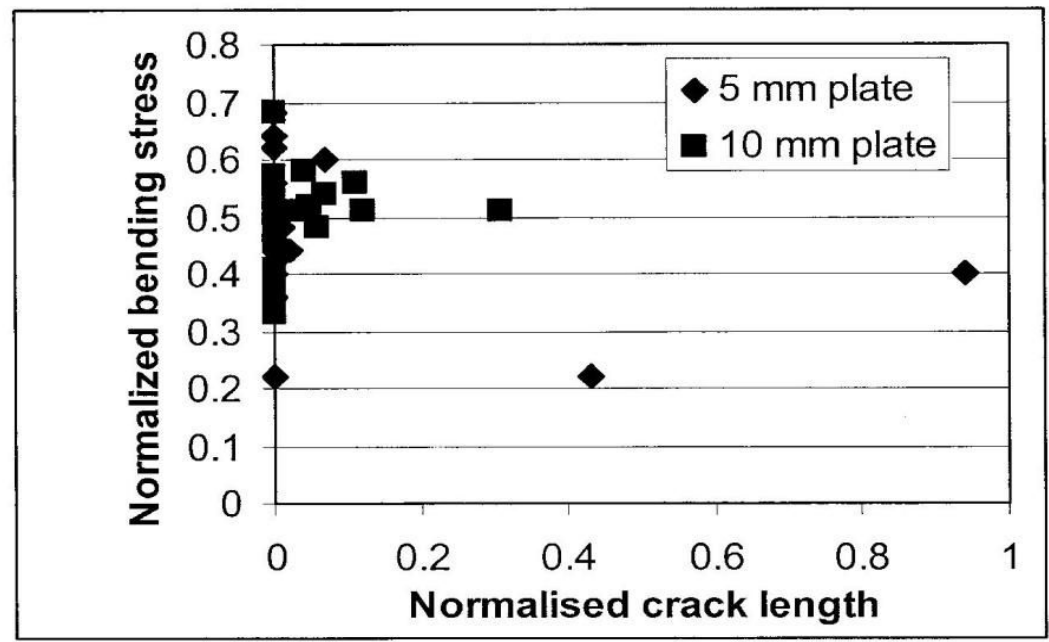

Fig. 10 Effect of crack lengths on bending strengths of $300 \times 300 \mathrm{~mm}$ LMO plate castings.

(iii) Effect of pouring temperature, pouring rate and plate thickness on porosity distribution and levels in alloy plate casting

In this work, samples with high apparent porosity levels were selected after studying radiographs and their porosity determined by density measurements. The interpretations of radiography results for side gated plates are shown in Figs. 11 and 12. The graphs also show density profile caused by solidification pattern. 
$\mathrm{R} 19,8^{\circ} 6^{\circ} \mathrm{C}, 106 \mathrm{ml} / \mathrm{s}$
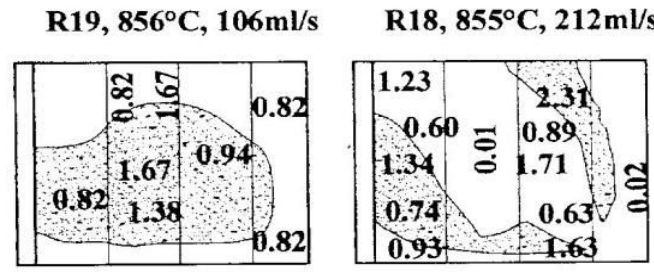

$\mathrm{R31}, \mathrm{704}^{\circ} \mathrm{C}, 205 \mathrm{ml} / \mathrm{s}$

$\mathrm{R} 27,7^{\circ} 3^{\circ} \mathrm{C}, 427 \mathrm{ml} / \mathrm{s}$
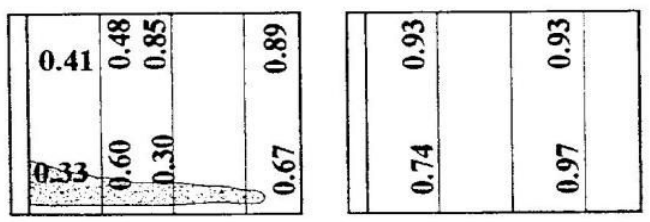

$\mathrm{R} 22,854^{\circ} \mathrm{C}, 427 \mathrm{ml} / \mathrm{s}$

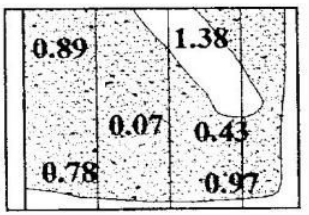

$\mathrm{R} 28,7^{\circ} \mathrm{C}, 427 \mathrm{mV} / \mathrm{s}$

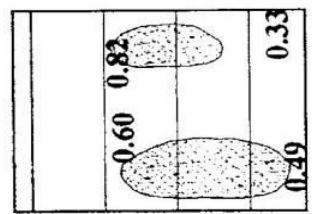

Fig. 11Tentative interpretation of porosity distribution in $5 \mathrm{~mm} \mathrm{LM} 25$ plates as observed from radiograph films, showing porosity distributions

R21, $850^{\circ} \mathrm{C}, 106 \mathrm{ml} / \mathrm{s}$

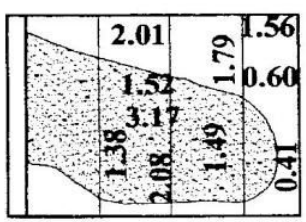

R26, $755^{\circ} \mathrm{C}, 427 \mathrm{ml} / \mathrm{s}$

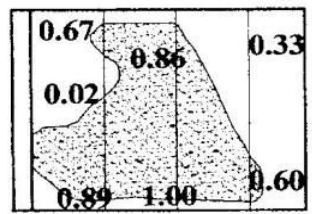

$\mathrm{R} 20,853^{\circ} \mathrm{C}, 205 \mathrm{mV} / \mathrm{s}$

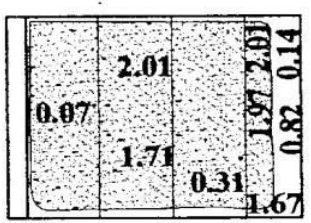

R30, $7^{\circ}{ }^{\circ} \mathrm{C}, 205 \mathrm{mV} / \mathrm{s}$

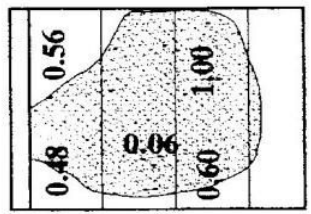

$\mathrm{R} 23,849^{\circ} \mathrm{C}, 427 \mathrm{mV} / \mathrm{s}$

$\mathrm{R25}, \mathbf{7 5 0}^{\circ} \mathrm{C}, \mathbf{2 0 5 \mathrm { ml } / \mathrm { s }}$
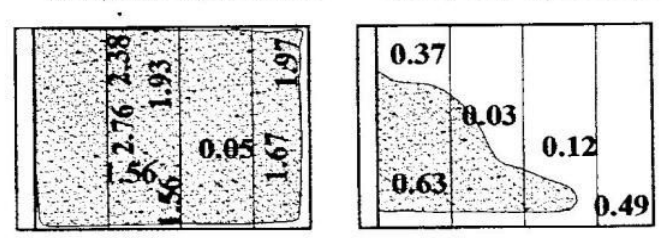

R29, $7^{\circ} 3^{\circ} \mathrm{C}, 427 \mathrm{mV} / \mathrm{s}$

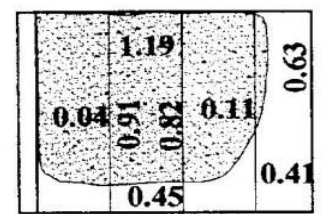

Fig. 12 Tentative interpretation of porosity distribution in $10 \mathrm{~mm}$ LM 25 plates as observed from radiograph films, showing porosity distributions.

Porosity data have been entered at locations it was measured. The radiographic pattern does not represent the distribution of porosity in the casting. Porosity distribution is high (up to 3\%) at position 2 for castings poured at $850^{\circ} \mathrm{C}$ temperature, and ranges between one and two percentages in other positions (Fig.13). Castings poured at high rate and high temperature experience solidification starting at the same time in the entire plate. No directional feeding took place and the plate exhibits porosity covering a wide area except at edges where there is the benefit of a temperature gradient because of chilling (side effect). Radiographs of castings in metal moulds carried out in previous experiments do not have porosity while those in Furan and Pepset sand castings; have porosity as observed by the author. 


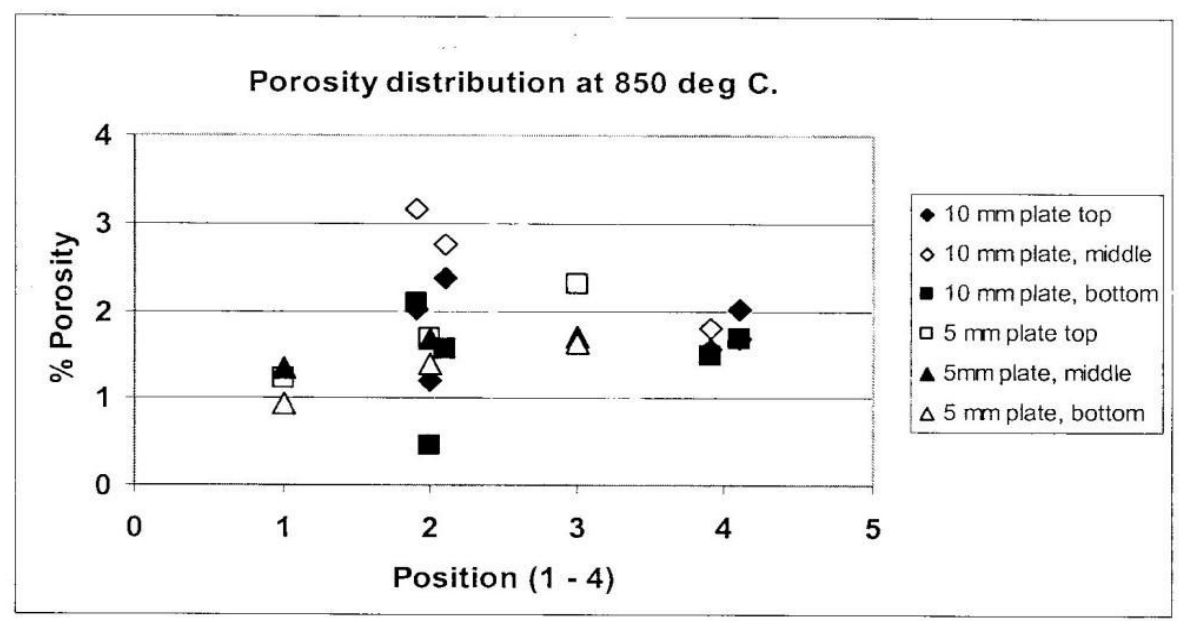

Fig. 13 Porosity distribution in selected position of LM 25 plate castings poured at $850^{\circ} \mathrm{C}$ at different pouring rates.

Low temperature pouring produces sounder castings but the distribution of porosity is, in general more complicated. The results shown in Fig. 13 indicate that at $850^{\circ} \mathrm{C}$, the highest value of porosity is in the middle of $10 \mathrm{~mm}$ plate and this type of porosity is probably mainly shrinkage porosity. In all cases, the porosity values were above $1 \%$ for all castings poured at higher temperatures. These results confirm that high pouring temperatures are bad for castings even when feeders are used.
Porosity distribution in plates as indicated fig. 14 shows how complicated the solidification in the side gated castings is. It does not follow a simple graded solidification pattern as might be expected in the side poured castings. Pouring temperature, pouring rate, plate thickness and pouring medium all affect plate soundness.

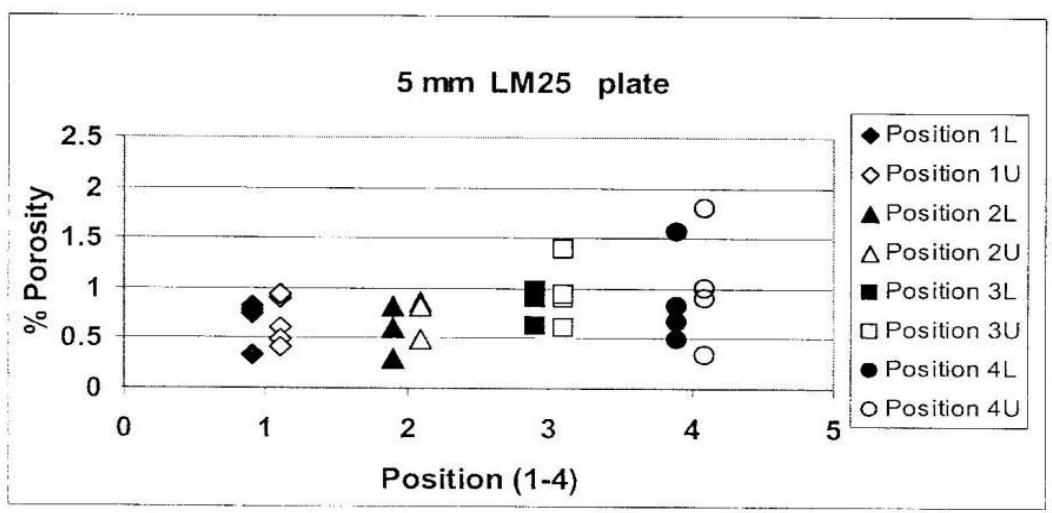




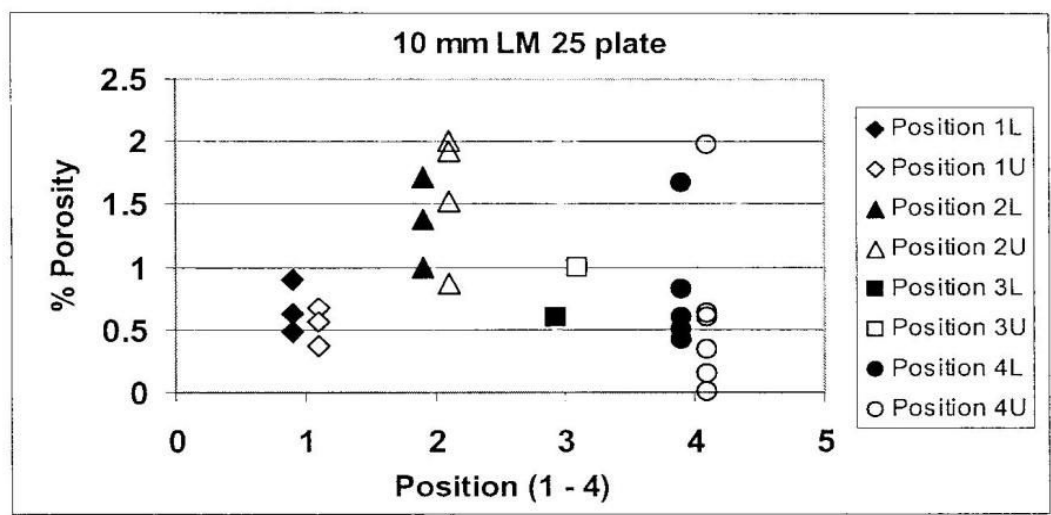

Fig. 14 Porosity distribution in four positions each divided into lower (L) and upper (U) sections in the $300 \times 300 \mathrm{~mm}$ LM 25 plate castings.

There is no temperature gradient and there is no directional solidification. There is a need to distinguish between shrinkage and gas porosity in order to interpret properly the radiography results. A list of clues for identifying internal defects in aluminum castings is available (Fleming, 1974, Bruner, 1981). The porosity observed in the present work show that it is a mixture of hydrogen gas porosity and shrinkage porosity. The shape of the hydrogen gas bubbles is generally round and the porosity may be uniformly dispersed in a casting. The size of individual gas bubble varies apparently approximately in proportion to dendrite arm spacing.

(iv) Influence of pouring temperature, pouring rate, and plate thickness on mechanical properties of alloy plate castings

The BS 1490 standard test specimen were tested until they failed by fracturing. The ultimate tensile strength, percentage elongation and percentage reduction in area for 5 and $10 \mathrm{~mm}$ plate castings are shown in Figs. 15, 16 and 17 respectively. The plate ultimate tensile strength values lies mainly between 50 and $60 \mathrm{MPa}$ especially at locations near the side feeder and at the edge of the plate. The strength values are very low especially for $5 \mathrm{~mm}$ plate $(35-50 \mathrm{MPa})$ in position 2 and 3 of the plates (Fig. 15).

With a few exceptions especially in $5 \mathrm{~mm}$ Plates, consistent tensile stress results were obtained when the metal was poured at temperature range of $700-750^{\circ} \mathrm{C}$ and pouring rates between 200 and $430 \mathrm{ml} / \mathrm{s}$. The strength values of $5 \mathrm{~mm}$ thickness plates are scattered compared to those of $10 \mathrm{~mm}$ plates. The scatter is expected due to volume effect of material tested. The smaller the volume of the specimen tested, the more the scatter. Fracture elongation values are between 10 to $50 \%$ for 5 and $10 \mathrm{~mm}$ plates while positions 2 and 3 having the lowest values (Fig. 16).

Over $70 \%$ of specimens with less than $25 \%$ elongation were in position 2 and 3 of the plate casting. This shows that position two and three in the casting have low strength and ductility values when compared to those taken from the edges. The percentage reduction in area lies between 10 to $60 \%$ for both 5 and $10 \mathrm{~mm}$ plates (Fig. 17). 

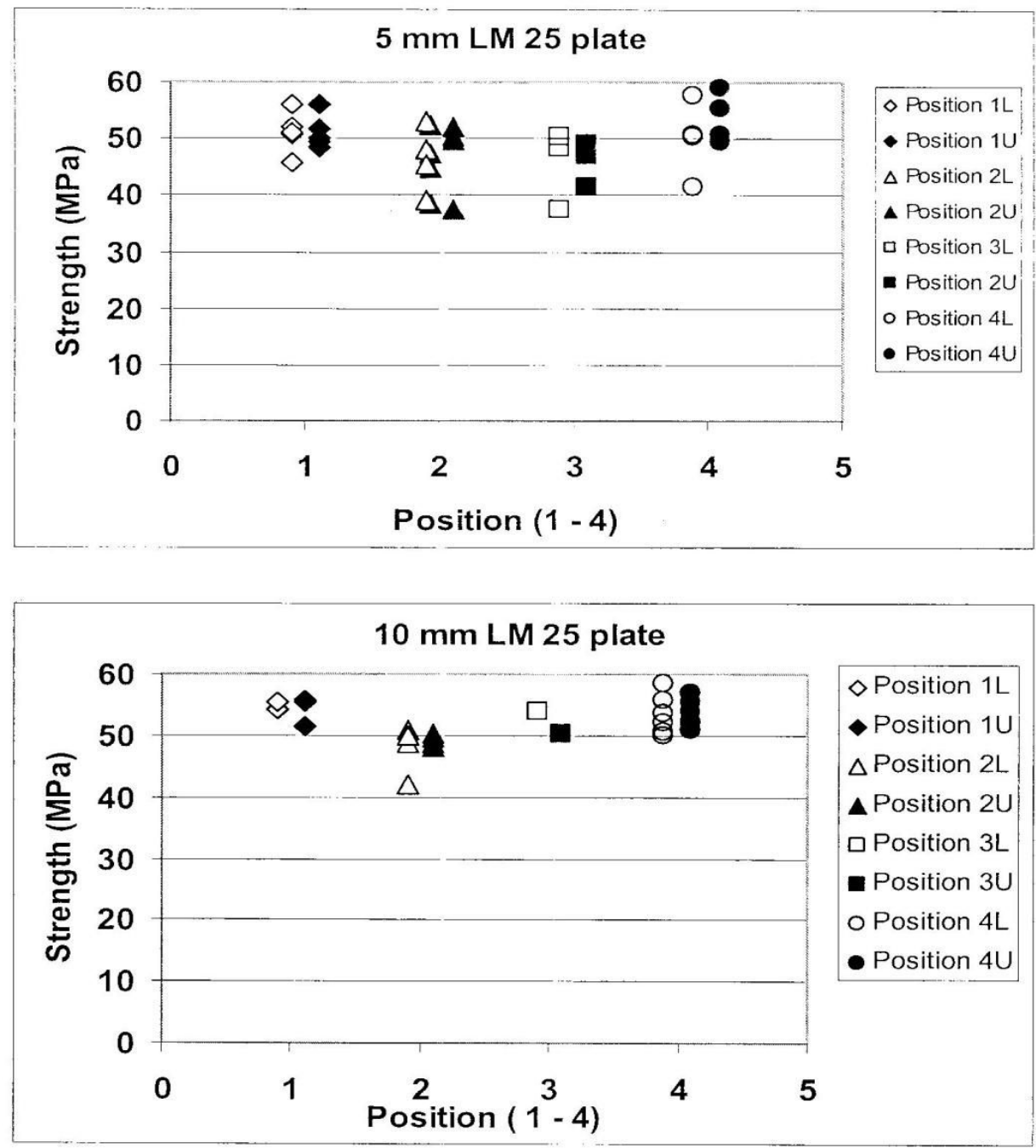

Fig. 15 Ultimate tensile strength $(\mathrm{MPa})$ distribution in samples taken in four positions each divided into lower (L) and upper (U) sections in the $300 \times 300 \mathrm{~mm}$ LM 25 plate castings.

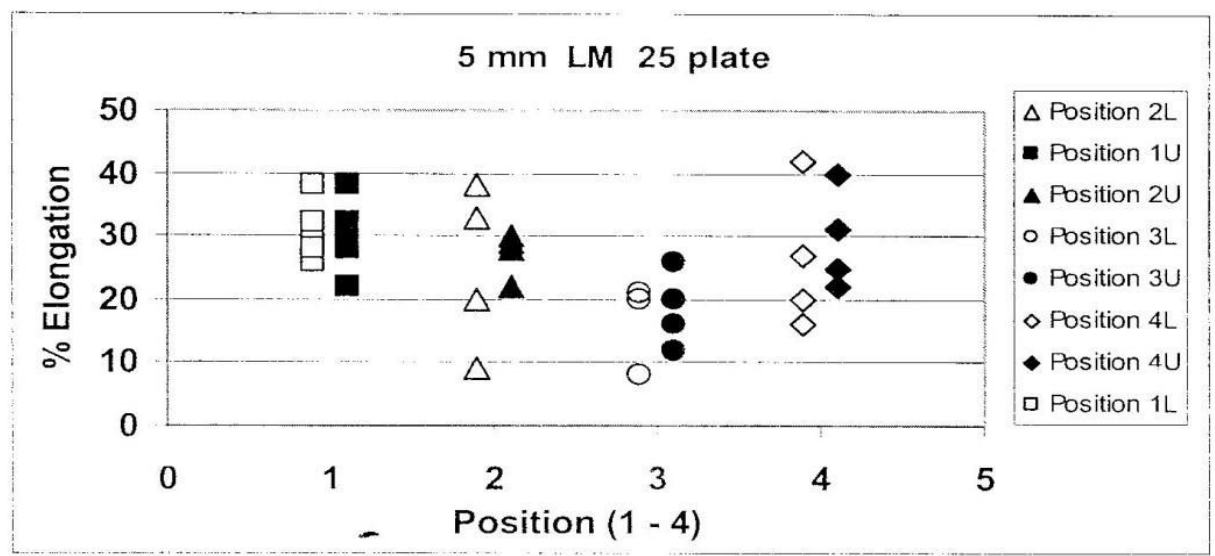




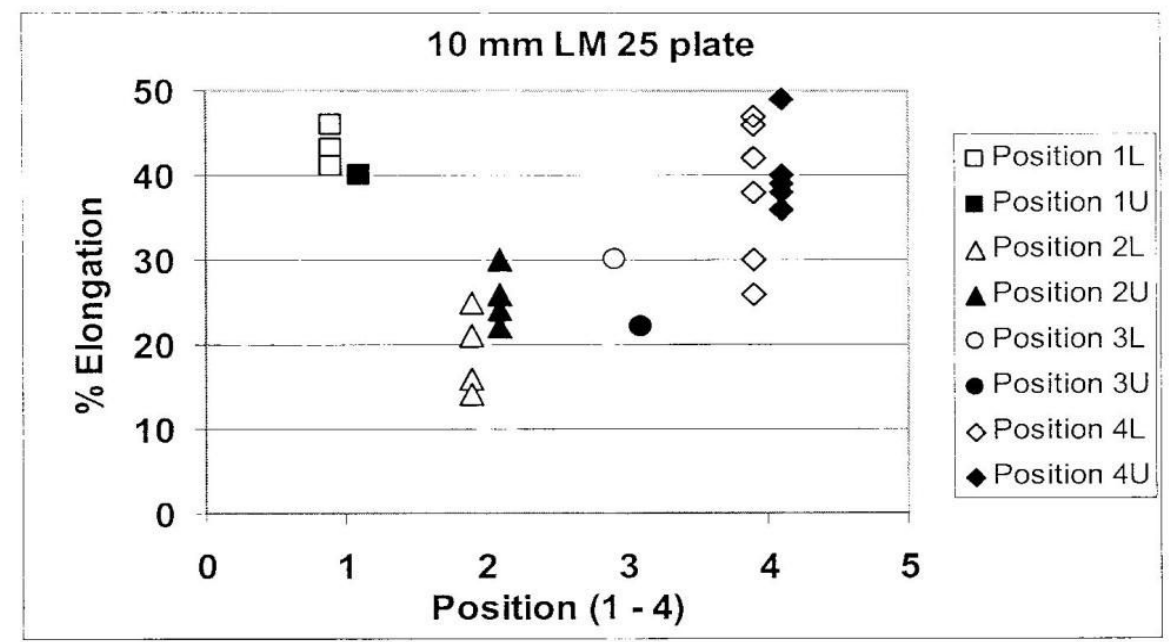

Fig. 16 Percentage elongation in samples taken in four positions each divided into lower (L) and upper (U) sections in the $300 \times 300 \mathrm{~mm}$ LM 25 plate castings.
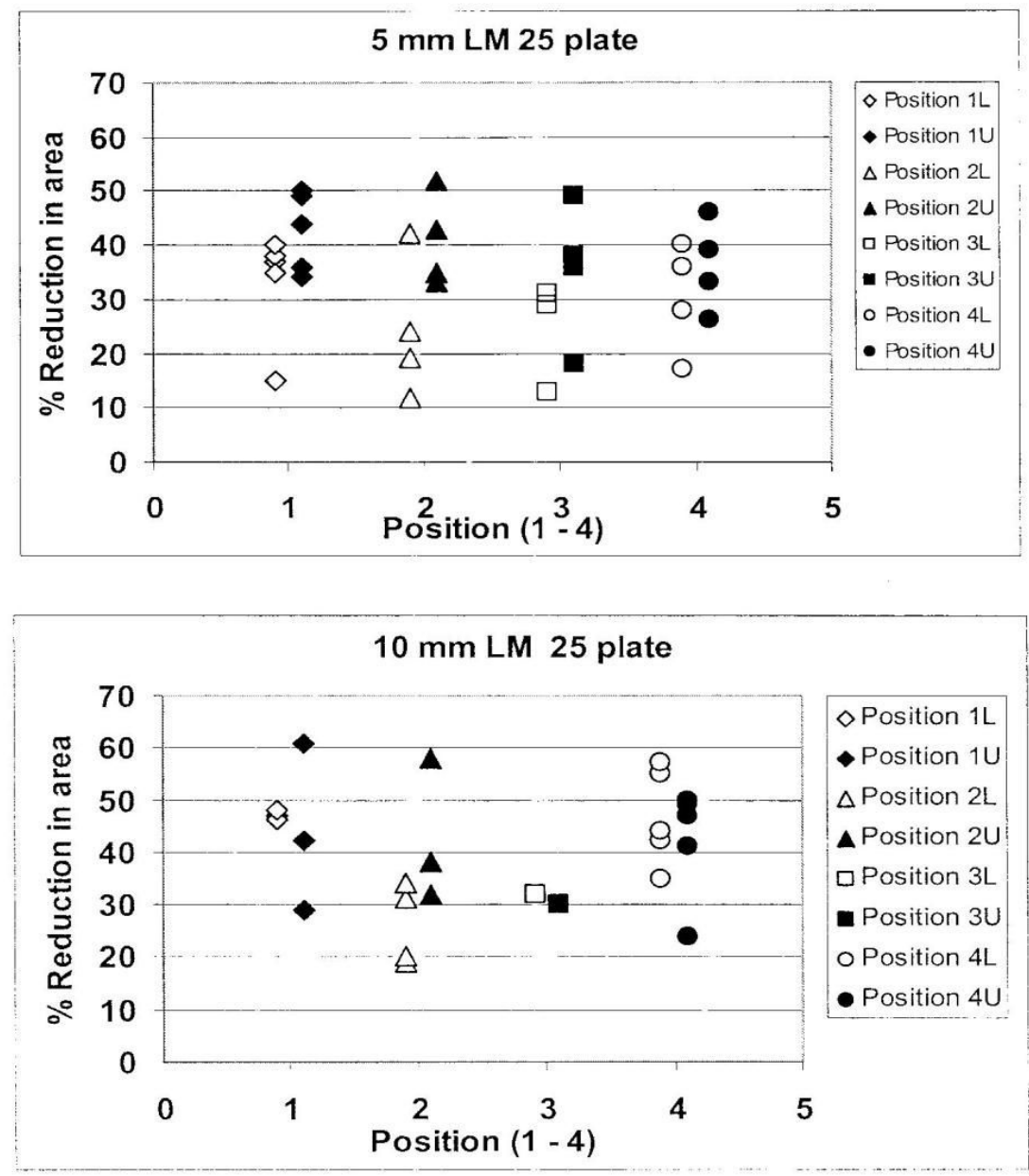

Fig. 17 Percentage reduction in area in samples taken in four positions each divided into lower (L) and upper (U) sections in the $300 \times 300 \mathrm{~mm}$ LM 25 plate castings. 

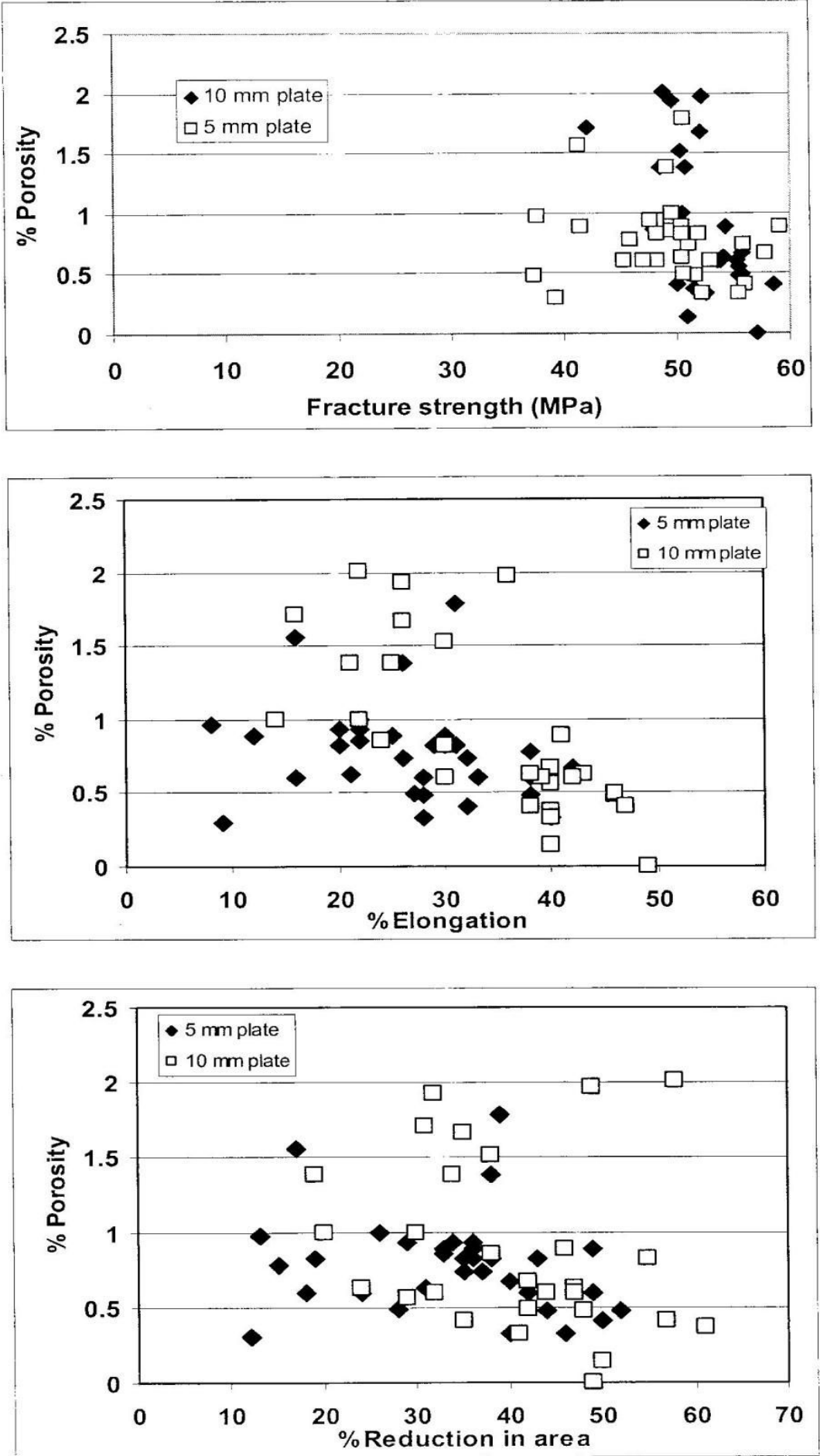

Fig. 18 Effect of porosity on strength, elongation and reduction in area of the $300 \times 300 \mathrm{~mm}$ LM 25 plates. 
Values are higher for tested specimen taken from the upper part of the $5 \mathrm{~mm}$ plate while in a $10 \mathrm{~mm}$ plate, the values are mixed up. For oxide forming castings, it seems that there is no relationship between percentage reductions in area, fracture strength and percentage elongation with porosity (Fig. 18). In the case of most metals, porosity increases with an increase in ductility. For aluminium alloys poured by side gating, the morphology and size of the oxide film rather than porosity determines the mechanical properties.

In most cases, micro porosity does not affect the structural strength of the component sufficiently to make the component unsuitable for its intended application except when there exists through wall porosity which may cause pressure tightness defects. Pressure leakage can be caused by interconnecting interdendritic and intergranular porosity and pore size will exert a significant effect (Bruner, 1981; Campbell, 2006). Experimental results in Fig.
$18 \mathrm{~b}$ indicate that the higher the porosity, the lower is the elongation.

Porosity has effect on elongation in normal pouring temperature range. The decrease in porosity from $1 \%$ to $0.5 \%$ increases elongation from $10 \%$ to $40 \%$. The ductility of material is seriously impaired by the presence of second phases especially pores (Shivkumar, 1990). Theoretically, uniformly graded properties across the plate would have been expected if the side feeding has been working properly along the direction of the temperature gradient. There exists a good correlation between elongations, reduction in area with fracture strength of LM 25 aluminum alloy (Fig. 19). The fracture strength decreases with decrease in elongation and or reduction in area. The results shows a wide scatter, and as mentioned earlier, this is caused by plate volume effect, the oxide films introduced on the surface of the flow when the liquid is flowing horizontally layer after layer, and poor metal feeding.

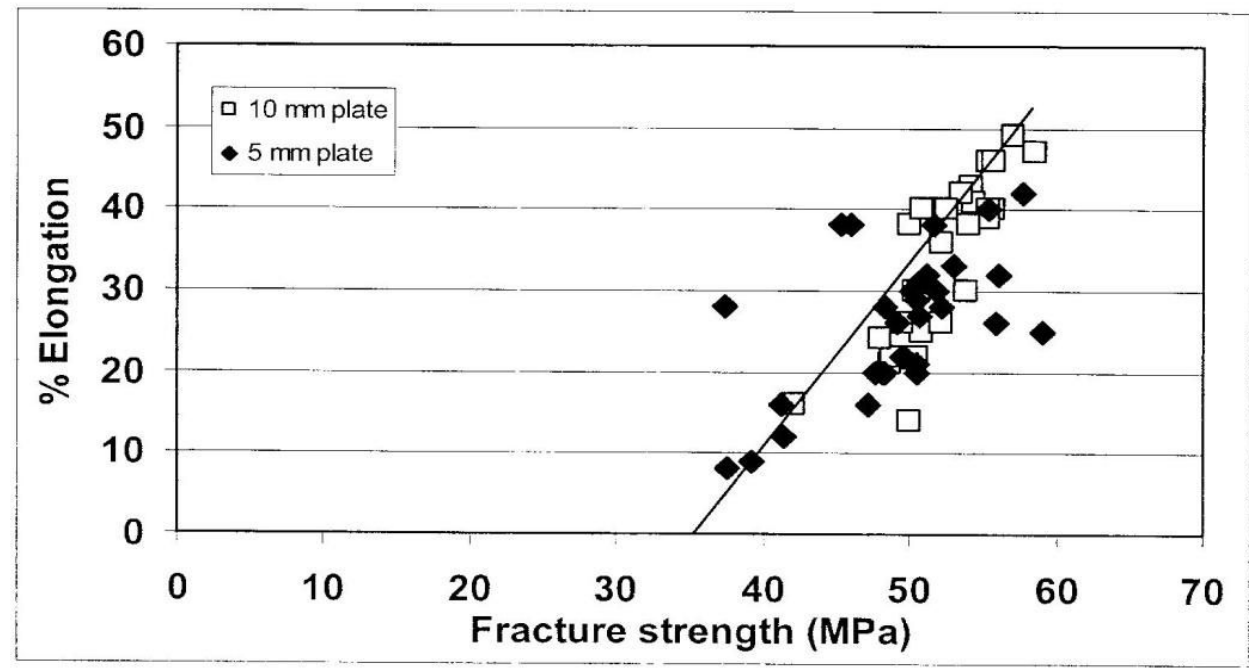




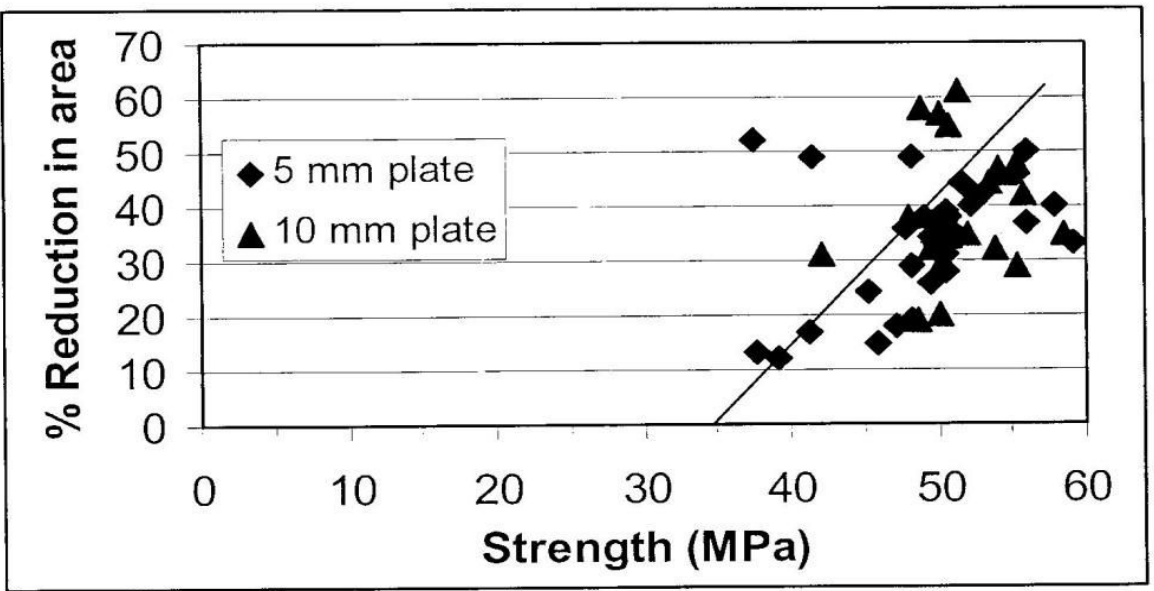

Fig. 19 Effect of elongation and reduction in area on strength of the $300 \times 300 \mathrm{~mm}$ LM 25 plates.

\section{(v) Effect of temperature on filling times}

The test results on filling times of LM25 cast plates are shown in Fig. 20. The results show that there is a relationship between filling time and pouring temperature for big castings such as the one used in the experiment. The lower pouring rates cause the metal to solidify and hinder the passage of liquid metal to fill the cavity. This can be seen clearly in the case of 5 and $10 \mathrm{~mm}$ plates poured at $106 \mathrm{ml} / \mathrm{s}$. It took more than twice the time to fill the last one third of the plate when compared with time taken to fill the first two thirds of the plate. It is difficult to present the mathematical model of filling of side gated plates with temperature as in some of the casting the flow of metal does not follow the theoretical passage and tend to tunnel through a semi-solidifying metal instead of passing through a side riser.

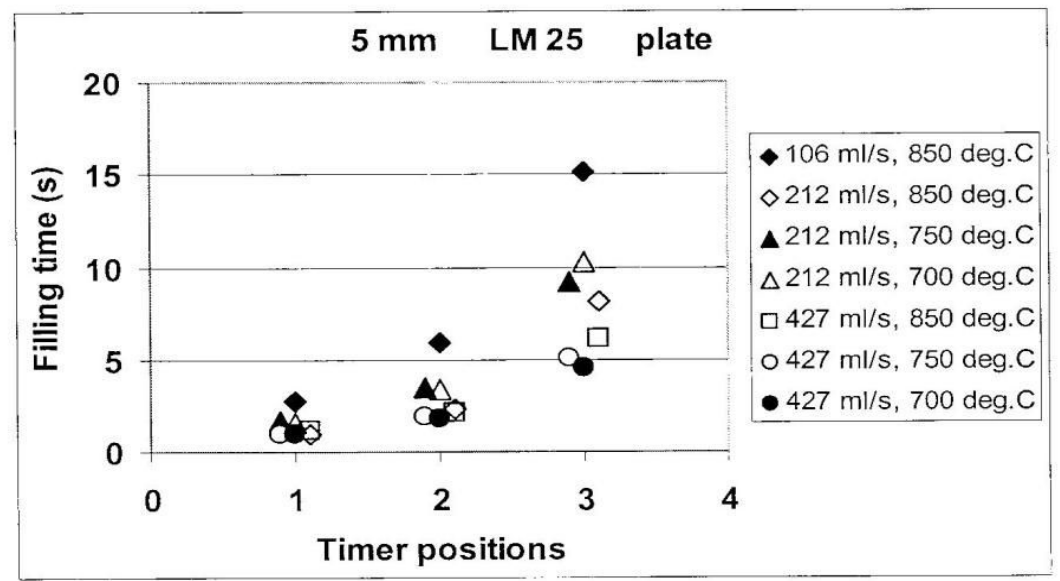




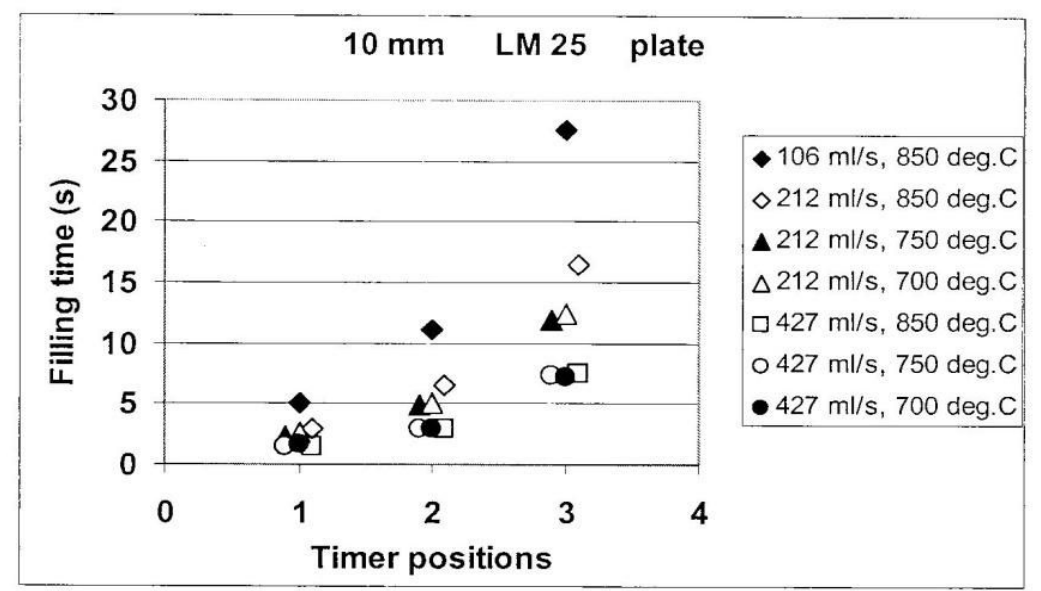

Fig. 20 Filling time (s) of the $300 \times 300 \mathrm{~mm}$ LM 25 plate castings. Timer position 1 is $1 / 3,2$ is $2 / 3$ and 3 is completed filling of the plate casting.

At higher pouring rates of $427 \mathrm{ml} / \mathrm{s}(1.07 \mathrm{~kg} / \mathrm{s})$, the filling was completed before substantial amount of solidification commenced in the temperature range of 700 to $850^{\circ} \mathrm{C}$. This explains why there is marked variation in pouring times experienced in industry when the pouring temperature is not controlled.

The coefficients of discharge $\left(C_{d}\right)$ values for side gated casting are affected by pouring temperature, pouring rates and plate thickness (Fig. 21). The $C_{d}$ value is calculated using the time used to fill the whole casting. At low pouring rates, the $C_{d}$ value is high for thinner plates than for thicker plates. For high pouring rates and thinner plates, the $C_{d}$ value is higher at low pouring temperatures. The $C_{d}$ value is constant for thicker plates at high pouring rates notwithstanding the pouring temperature.

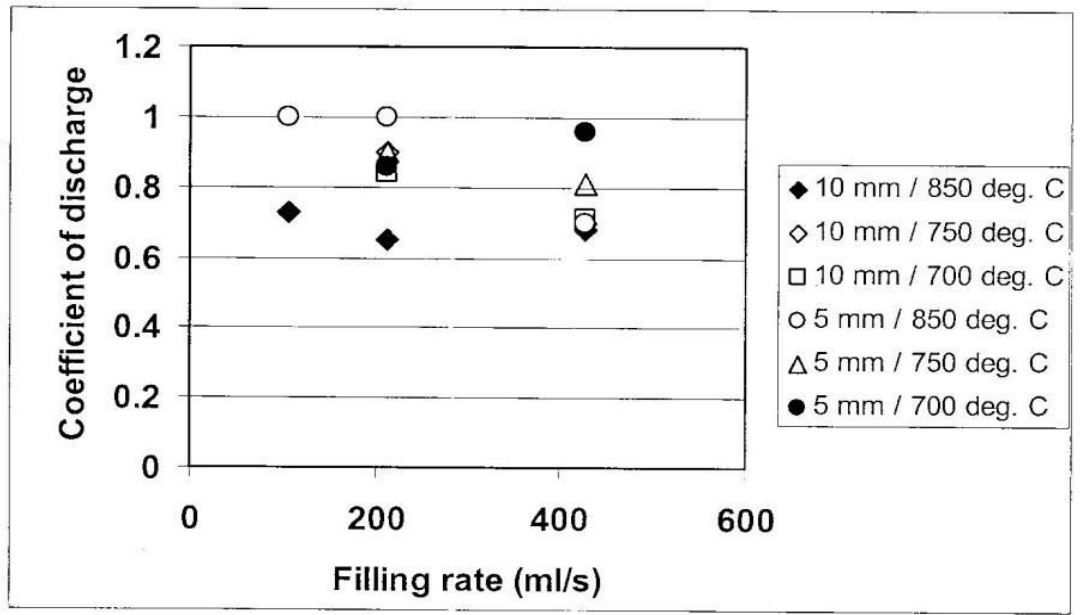

Fig. 21 Coefficient of discharge for the filling of $300 \times 300 \mathrm{~mm}$ LM 25 plate castings at different filling rates and temperatures.

(vi) General observations on mechanical properties of LM25

As shown in Table 1. The LM25 (A356.0) is aluminium alloy containing $7 \% \mathrm{Si}$ and $0.3 \%$ $\mathrm{Mg}$. Chemical composition range 6.5 to $7.5 \% \mathrm{Si}$, and 0.20 to $0.45 \% \mathrm{Mg}$. The alloy has liquidus and solidus temperatures of 615 and $555^{\circ} \mathrm{C}$ respectively. This indicates that the superheat was 85,135 , and $235^{\circ} \mathrm{C}$ in relation to pouring temperature. The recommended casting temperature of this alloy is 675 to $790{ }^{\circ} \mathrm{C}$. (Metals handbook, 1990). The values are within 
the range used in the experiment. Typical properties of as cast LM25 alloy test bars are $227 \mathrm{MPa}$ with $3.5 \%$ elongation. The values obtained in this experiment are lower in strength due to oxide films formed layer by layer as the metal is being fed on top of each layer. No attempts were made to compare the LMO and LM25 test results as the reason for carrying out the experiment was not to compare the properties of these two alloys.

\section{CONCLUSIONS}

1. High pouring temperature and pouring rates in sand molds gives uneven thickness along the plate castings. Plates poured at low rates put high temperature or vice versa gives consistent thickness values.

2. Over half of $5 \mathrm{~mm}$ plate castings poured at $850^{\circ} \mathrm{C}$, and $36 \%$ of all $10 \mathrm{~mm}$ plates tested failed by cracking (0xide films opening up) while in most cases exhibiting high bending stresses.

3. The longest cracks in both material thicknesses occurred at a distance of 150 to 225 from the side riser (Position No.3). This was maybe the onset of oxide laps formation. Over half of all cracks were less than $3 \mathrm{~mm}$ in length.

4. Low pouring temperatures produces sounder castings. As the pouring temperature increases, so is the porosity ( 0.1 to $3 \%)$, but porosity distribution is complicated due to the absence of directional solidification.

5. The ultimate strength of the plate lies between $50-60 \mathrm{MPa}$ on the sides and $35-$ $50 \mathrm{MPa}$ in the middle of plate at distances 75 to 225 from the side riser. The strength scatter is found more in thin section plate.

6. Presence of oxide films in the aluminum alloy makes it difficult to relate elongation with reduction in area of the alloy.

7. There is a correlation between casting filling time, pouring rate, coefficient of discharge and plate thickness.

8. The use of a conventional side gating and feeding technique results in severe porosity in the casting.

\section{ACKNOWLEDGMENTS}

The author is grateful to the University of Dar es salaam and the University of Birmingham for supporting the research work.

\section{REFERENCES}

Bruner, R.W. (1981). "Fractures: Positive identification of internal defects in aluminum castings." AFS Vol. 89 pp. 627 632

Campbell, J., (1990). "Materials Perspective Entrainment defects". Materials Science and Technology Vol. 22 No. 2 (2006) 127145

Campbell, J., (2003) "Castings," Butterworth Heinemann.

Eklund, J.E., (1991). “On the effects of impurities on the solidification and mechanical behavior of primary and secondary commercial purity aluminum and aluminum alloys" Ph.D thesis publication, Faculty of Mechanical Engineering, Helsinki University of Technology.

Flemings, G., (1974). "Solidification processing" Materials Science and Engineering Series McGraw-Hill Inc.

Metals Handbook, (1990) Properties and Selection: Nonferrous Alloys and SpecialPurpose Materials. ASM International, Vol. $210^{\text {th }}$ Ed.

Runyoro, J., (2006). Relationships between fracture strength and thickness of aluminum oxide film on top of liquid aluminum. Paper sent to EAJE for review and publication.

Shivkumar, S, Apelian, D, and Zou, J., (1990) "Modeling of Microstructures evolution and Micro-porosity Formation in Cast low strength and ductility values when compared to those taken from the edges. The percentage reduction in area lies between 10 to $60 \%$ for both 5 and 10 mm plates (Fig. 17).

Aluminum Alloys." AFS Vol. 98 pp 897-904 